\title{
Quanto vale o trabalho do professor? Desvelando o processo de desvalorização salarial em Ponta Grossa - PR
}

\author{
How much is the teachers' job worth? Revealing the \\ devaluation process of teachers' salaries in the city \\ of Ponta Grossa
}

\section{¿Cuánto vale el trabajo del profesor? Desvelando el proceso de desvalorización del salario en Ponta Grossa - PR}

\section{Simone de Fátima Flach*}

\begin{abstract}
Resumo: Pretende-se, através da análise das principais decisões político-educacionais, desvelar o processo de desvalorização do trabalho do professor em curso no município de Ponta Grossa - Paraná, a partir da reforma legal municipal ocorrida no período 2005-2010. Apresenta-se a configuração da carreira docente no contexto municipal antes e depois de sua reorganização, a qual teve como principal aporte legal o piso salarial nacional instituído pela Lei $n^{\circ} 11.738 / 2008$. Conclui-se que a reforma realizada com base nos pressupostos do novo gerencialismo tornou a carreira docente pouco atrativa aos professores ingressantes, criou situações desiguais em relação ao avanço salarial ao longo da carreira e evidenciou a fragilidade do compromisso para uma educação de qualidade.
\end{abstract}

Palavras-chave: Carreira docente. Trabalho docente. Valorização docente.

\begin{abstract}
The aim of this paper is to analyze the main educational political decisions in order to unveil the process of devaluing teacher practice that is taking place in the city of Ponta Grossa, PR. The analysis focuses on the period from 2005 to 2010 after the municipal legal reform. The article presents the configuration of the teaching career in the local context before and after its reorganization, which had as its main legal basis the national salary implemented by Law 11738/2008. The study demonstrates that the reform based on the new management's assumptions made the career less attractive to
\end{abstract}

\footnotetext{
* Professora do Programa de Pós-Graduação em Educação da Universidade Estadual de Ponta Grossa UEPG. E-mail: <eflach@uol.com.br>
} 
new professionals. Also, it created unequal situations concerning the increase of salaries along the career and highlighted the fragility of the commitment to quality education.

Keywords: Teaching career. Teaching practice. Teaching valuing.

Resumen: Se pretende, a través del análisis de las principales decisiones políticoeducacionales, desvelar el proceso de desvalorización del trabajo del profesor en curso en el municipio de Ponta Grossa - Paraná, a partir de la reforma legal municipal llevada a cabo en el período 2005 - 2010. Se presenta la configuración de la carrera docente en el contexto municipal antes y después de su reorganización, la cual recibió como principal aportación legal el piso mínimo nacional instituido por la Ley n $\mathrm{n}^{\mathrm{0}}$ 11.738/08. Se concluye que la reforma realizada en base a los presupuestos del nuevo gerencialismo volvió poco atractiva la carrera docente a los profesores ingresantes, generó situaciones desiguales con relación al avance salarial a lo largo de la carrera y evidenció la debilidad del compromiso hacia una educación de calidad.

Palabras clave: Carrera docente. Trabajo docente. Valorización docente.

\section{Introdução}

Entre os vários aspectos que marcam a profissão docente no Brasil, um se destaca e se torna central na análise pretendida, por ser aquele que oferece a sustentação material para a sobrevivência, formação, informação e, se ainda houver possibilidade, lazer dos professores: a questão salarial. Em uma sociedade capitalista, onde o trabalhador vende sua força de trabalho, discutir a questão salarial é uma tarefa deveras ingrata, devido aos inúmeros condicionantes que se entrelaçam e tornam a sua elucidação controversa. No entanto, no bojo da luta por melhores salários e condições de trabalho, estão presentes não apenas o empobrecimento econômico constante e crescente, mas também a depauperação do processo formativo e do conhecimento específico da classe docente. As consequências desse processo são graves e não podem ser ocultadas ou desconsideradas, visto que

[...] nenhuma reforma ou proposta educacional que objetive a melhoria da qualidade de ensino na escola pública brasileira obterá bons resultados sem que a condição salarial dos professores seja tratada condignamente. (FERREIRA JR.; BITTAR, 2006, p. 16).

A valorização dos profissionais da educação, em especial da Educação Básica, no contexto brasileiro, é questão complexa. Os interesses econômicos, políticos e ideológicos envolvidos na trama onde se insere a valorização dos professores brasileiros não são fáceis de serem desvelados. Por isso, o texto aqui apresentado é uma tentativa, inicial e limitada, de desvelar a maneira como a desvalorização do trabalho foi reafirmada pela legislação, tendo o consentimento tácito da categoria, a qual foi incapaz de perceber longitudinalmente os efeitos da reforma implementada. 
Sob um discurso de "valorização" pautado no novo gerencialismo, a reforma não permitiu a percepção e mobilização dos profissionais já atuantes, desvalorizou a carreira, negou conquistas históricas, criou situações de desigualdade salarial entre profissionais, além de tornar a carreira docente pouco atrativa aos professores iniciantes.

Entender essas relações, suas contradições e vislumbrar possibilidades para a carreira docente nessa realidade é o desafio posto no presente artigo.

\section{A questão salarial dos professores e o piso salarial nacional}

Os professores brasileiros, em especial aqueles que se dedicam ao início da formação educacional de crianças, nunca foram remunerados adequadamente, conforme apontam pesquisas variadas a respeito da questão (CAMPOS, 2002; TANURI, 2000; RABELO, 2010; entre outros). Segundo Campos (2002), o desprestígio da profissão e a remuneração inadequada, além do despreparo profissional, são resquícios da tradição educacional brasileira, quando a adoção de "mestres-escolas" foi necessária para suprir algumas lacunas não preenchidas por outras ordens religiosas quando houve a expulsão dos jesuítas em 1759.

Rabelo (2010), ao realizar um retrospecto do salário do professor no Brasil, apresenta situações específicas nas regiões, apontando como a não valorização do trabalho docente esteve presente ao longo da expansão da oferta educacional para a população. A partir dos estudos de Fernandes (2000), a autora apresenta algumas situações importantes para a reflexão aqui proposta:

O autor descreve a situação de abandono das escolas estatais de Primeiras Letras da Paraíba, em 1821, que não encontravam quem ensinasse pelo baixo salário oferecido. No Maranhão, em 1822, manda-se elaborar editais para contrata professores com ordenados tão baixos que se propunha o dobro para que ele desse para mínima subsistência. A situação é idêntica em Pernambuco e no Piauí: a carência de professores era atribuída aos baixos salários e à falta de pessoas "instruídas e idôneas" que pudessem ensinar. No Piauí, existiam, três escolas quase sempre vagas porque não havia quem aceitasse receber um salário que era menor do que $1 / 3$ do que recebia um feitor de escravos (com cama e mesa). (RABELO, 2010, p. 57).

Com remuneração baixa, a profissão docente pode ser considerada como aquela passível de ser exercida por quem tivesse outra atividade profissional ou que não dependesse exclusivamente do salário dessa atividade para sobreviver. Essa é uma das condições que justifica a existência de um universo quase que exclusivamente feminino na atuação da docência destinada às crianças, em especial para aquelas com idade entre 0 a 10 anos, visto que as mulheres poderiam passar da função de "rainhas do lar" para "educadoras da infância", profissão 
essa caracterizada por um misto de missão, vocação e devoção incontestes. Nesse universo, a questão salarial poderia ser relegada a segundo plano, sob pena de macular tão sublime ação laboral.

É importante ressaltar que, no início da República, as escolas normais cresceram e as mulheres puderam estar mais presentes nesse processo de formação. No entanto, os homens que ingressavam no magistério "aspiravam a cargos de chefia e direção, diferentemente das mulheres, que permaneciam nas salas de aula" (ALMEIDA, 2004, p. 77). Conforme a autora, a expansão da oferta de recursos humanos para o ensino primário seguia a lógica conservadora da sociedade brasileira, segundo a qual os lares não se privariam da ausência feminina mesmo que tivessem que cuidar e educar de crianças, destino que deveria ser cumprido naturalmente. Nesse contexto, a questão docente não assume a centralidade necessária para a discussão das condições objetivas de trabalho, tais como a imperiosa prioridade de recursos materiais, humanos e financeiros, no qual se insere o salário dos profissionais. TANURI (2000) afirma que a possibilidade de conciliar as funções domésticas com outra atividade no exercício do magistério foi um impeditivo para a profissionalização, e os baixos salários oferecidos repeliram o elemento masculino da profissão, visto que este socialmente deveria ser o "arrimo" de família.

A constituição da carreira docente no Brasil e a consequente remuneração dos profissionais estiveram vinculadas, ao longo dos anos, aos interesses sociais e políticos que não viam a carreira articulada com as reais necessidades dos educadores, enquanto trabalhadores em geral. Nesse contexto, a melhoria do processo educativo, através da necessária formação adequada de professores, o acesso aos quadros docentes (principalmente no ensino público) e o consequente reflexo dessas ações nos resultados do rendimento dos alunos ficou deficitária.

A valorização dos professores tem assumido centralidade nas ações políticas das últimas décadas. As ações que pretendem a valorização docente visam, de forma geral, resgatar o déficit histórico sofrido por esses profissionais em termos de remuneração e formação profissional. No entanto, essas ações têm ficado aquém das reais necessidades dos profissionais no atual contexto histórico. Com a Constituição Federal de 1988, restou claro que os gestores públicos de estados e municípios devem promover a valorização dos profissionais do magistério e de melhoria da qualidade do ensino. A previsão constitucional está expressa no inciso V do artigo 206, ao estabelecer como princípio a "valorização dos profissionais" e a garantia de "plano de carreira com ingresso exclusivo por concurso público de provas e títulos", além de deixar claro que deveria ser criado o piso nacional para os profissionais do magistério (BRASIL, 1988) ${ }^{1}$. No

\footnotetext{
${ }^{1} \mathrm{O}$ texto do inciso V do artigo 206 assim definia: “ valorização dos profissionais do ensino, garantido, na forma da lei, plano de carreira para o magistério público, com piso salarial profissional e ingresso exclusivamente
} 
entanto, a previsão constitucional só tornou-se real depois de duas décadas, quando foi aprovada a Lei Federal no 11.738/2008 (BRASIL, 2008), que criou o piso nacional para os profissionais do magistério, juntamente com a sua jornada e forma de reajuste, conforme veremos.

A Lei de Diretrizes e Bases da Educação Nacional - LDB (BRASIL, 1996b) reforçou os princípios constitucionais no Título VI de seu texto (artigos 61 a 67), intitulado, Dos Profissionais da Educação, estabelecendo as diretrizes para a formação dos profissionais do magistério e deixando clara a responsabilidade dos Sistemas de Ensino na valorização desses profissionais, além de orientações para a elaboração de estatutos e planos de carreira para o magistério público. É preciso considerar, ainda, que concomitante ao trâmite final da LDB, a Emenda Constitucional no 14, de 12 de setembro de 1996 (BRASIL, 1996a), criou o Fundo de Manutenção e Desenvolvimento do Ensino Fundamental e de Valorização do Magistério - FUNDEF, regulamentado posteriormente pela Lei $n^{\circ}$ 9.424/96 (BRASIL, 1996c), a qual estabelecia em seu art. $9^{\circ}$ que Estados, o Distrito Federal e os Municípios deveriam, no prazo de seis meses, dispor de novo Plano de Carreira e Remuneração do Magistério, assegurando remuneração condigna aos professores do ensino fundamental público, em efetivo exercício do magistério. Mesmo após todas essas regulamentações, o piso salarial dos professores não se efetivou de forma uniforme, restando aos poderes locais (municipais e estaduais) estabelecerem em seus planos de carreira a forma de remuneração e valorização do magistério.

Ao ampliar a cobertura dada pelo FUNDEF, através do Fundo de Manutenção e Desenvolvimento da Educação Básica e de Valorização dos Profissionais da Educação - FUNDEB, criado pela Emenda Constitucional n ${ }^{\circ}$ 53, de 20 de dezembro de 2006 (BRASIL, 2006) e regulamentado pela Lei $\mathrm{n}^{\circ}$ 11.494, de 20 de junho de 2007 (BRASIL, 2007b), a questão salarial ganhou nova configuração, visto que o novo fundo foi criado para atender toda a educação básica e modalidades. No entanto, a efetividade prática da norma mostrouse limitada em razão das condições locais, uma vez que a complementação financeira da União não ocorreu conforme as necessidades reais.

A Emenda Constitucional n 53 estabeleceu o "piso salarial profissional nacional para os profissionais da educação escolar pública, nos termos da lei federal" (BRASIL, 2006), como um dos princípios sobre os quais se assenta a educação brasileira, conforme previsto no inciso VIII do art. 206 da Constituição

por concurso público de provas e títulos, assegurado regime jurídico único para todas as instituições mantidas pela União;" (BRASIL, 1988, grifo nosso). A redação dada pela Emenda Constitucional no 53 de 2006 assim estabelece: "valorização dos profissionais da educação escolar, garantidos, na forma da lei, planos de carreira, com ingresso exclusivamente por concurso público de provas e títulos, aos das redes públicas;", tendo sido incluído o inciso VIII, assim estabelecendo: "piso salarial profissional nacional para os profissionais da educação escolar pública, nos termos de lei federal.” (BRASIL, 2006, grifo nosso). 
Federal (BRASIL, 1988). Ainda, a mesma emenda previu a necessidade do estabelecimento legal de prazos para o poder público elaborar ou adequar seus planos de carreira (parágrafo único do artigo 206 da Constituição Federal - conforme redação incluída pela Emenda Constitucional n ${ }^{\circ} 53$ ). Este prazo foi regulamentado pela Lei $\mathrm{n}^{\mathrm{o}} 11.494$, de 20 de junho de 2007, quando esta estabeleceu em seu artigo 41 que "o poder público deverá fixar, em lei específica, até 31 de agosto de 2007, piso salarial profissional nacional para os profissionais do magistério público da educação básica.” (BRASIL, 2007b).

É importante destacar que a fixação de um piso salarial profissional nacional para os profissionais do magistério público da Educação Básica não ocorreu sem conflitos, pois inúmeras discussões, capitaneadas pelo Ministério da Educação, foram realizadas com representantes do poder público, estaduais e municipais. Essas discussões sempre foram controversas devido ao fato de que a responsabilidade financeira com a remuneração ficaria com os poderes locais, os quais, em sua maioria não possuíam recursos suficientes para garantir um padrão mínimo de remuneração para os profissionais. Além dessas questões, é preciso considerar que a definição de um piso nacional profissional para o magistério foi, também, resultado de luta de órgãos representativos da classe (dentre os quais a CNTE - Confederação Nacional dos Trabalhadores em Educação) e órgãos de defesa da educação, institucionais ou não, tais como universidades, conselhos de educação, dentre outros.

O piso salarial nacional para os profissionais do magistério foi instituído através da Lei $\mathrm{n}^{\circ} 11.738$, de 16 de julho de 2008 (BRASIL, 2008), e trouxe consigo a contradição de representar um avanço para o contexto educacional brasileiro, dadas as dificuldades e diferenças regionais relativas à remuneração dos trabalhadores e, ainda, o limite de não traduzir as expectativas da categoria que esperava maior valorização pelo trabalho docente. Ao ser instituído em 2008, o piso salarial profissional para o magistério teve como referência a jornada de 40 horas semanais de trabalho docente (art. $2^{\circ}$ ), sendo essa composta pelas atividades pedagógicas em sala de aula e atividades extraclasse, respeitando-se a proporção de $2 / 3$ (dois terços) da carga horária para o desempenho das atividades de interação com os educandos $\left(\mathbb{\int} 4^{\circ}\right.$ do art. $\left.2^{\circ}\right)$. Essa proposta de composição da carga horária, em atividades em classe e extraclasse, poderia representar melhoria ao desempenho profissional, visto que materializaria melhores condições de trabalho docente, podendo refletir na qualidade do ensino brasileiro ${ }^{2}$.

\footnotetext{
${ }^{2}$ Ao ser criado em 2008, o valor do piso salarial nacional para professores tinha o valor de $\mathrm{R} \$ 950,00$. Em 2010 , o valor reajustado estava em R $\$ 1.024,00$. É importante destacar que os estados do Ceará, Mato Grosso do Sul, Paraná, Santa Catarina e Rio Grande do Sul questionaram judicialmente a constitucionalidade da Lei 11.738/08 (BRASIL, 2008). No entanto, em 2011, o Supremo Tribunal Federal manteve a instituição do piso salarial nacional para os professores da educação básica, considerando a previsão constitucional para tal.
} 
O piso nacional profissional é um valor mínimo inicial para as carreiras docentes do ensino público. Também é preciso considerar que o início da carreira docente foi previsto para os profissionais com a formação mínima prevista pelo art. 62 da Lei n 9.394/96 - LDB (BRASIL, 1996b), ou seja, formação de nível médio na modalidade normal. A isso equivale ressaltar que os profissionais com formação superior precisam ter remuneração acima do mínimo estabelecido conforme preceito do art. 67, inciso VI da LDB através de progressão funcional por titulação ou habilitação nos termos dos planos de carreira específicos.

A Lei no 11.738 (BRASIL, 2008) estabeleceu o prazo até 31 de dezembro de 2009 para os governos (da União, Estados, Distrito Federal e Municípios) elaborarem ou adequarem seus Planos de Carreira e Remuneração do Magistério visando o cumprimento do piso salarial profissional nacional para os profissionais do magistério público da educação básica, conforme disposto no parágrafo único do art. 206 da Constituição Federal (BRASIL, 1988). A partir do estabelecimento desse prazo, a adequação dos Planos de Carreira e Remuneração do Magistério já existentes passou, gradativamente, por reformulações necessárias para o atendimento do disposto legal. No entanto, é preciso ressaltar que as reformulações e adequações previstas nem sempre ocorreram em prol da melhoria das condições salariais e de trabalho dos profissionais da educação, conforme caso em específico a ser analisado no presente texto.

\section{Situando a carreira docente no contexto municipal}

Ponta Grossa é um município localizado no centro sul do estado do Paraná, na região denominada Campos Gerais, sendo o quarto município mais populoso do estado com uma população de 311.611 habitantes, segundo o Censo Populacional - IBGE de 2010. O município se apresenta entre as maiores economias do estado do Paraná e no ano de 2007 ficou posicionado entre as 100 cidades mais ricas do Brasil (79 a colocação), com o Produto Interno Bruto chegando ao valor de $\mathrm{R} \$$ 4.930.947.000 (quatro bilhões, novecentos e trinta milhões, novecentos e quarenta e sete mil reais). O parque industrial de Ponta Grossa é o terceiro do estado do Paraná, movimentando principalmente a agroindústria ${ }^{3}$, abrigando o maior complexo armazenador de grãos do Brasil, pois recebe quase a totalidade da produção do Paraná, e parte da produção paraguaia e dos estados do Mato Grosso e Mato Grosso do Sul. Apesar da situação econômica privilegiada, os indicadores sociais do município demonstram que a desigualdade social se faz presente, não fugindo à regra das cidades brasileiras de mesmo patamar econômico. Mesmo apresentando um

\footnotetext{
${ }^{3} \mathrm{O}$ principal produto que movimenta a agroindústria na região é a soja. Ponta Grossa detém o título de "Capital Mundial da Soja” em razão do armazenamento e esmagamento de grãos.
} 
Índice de Desenvolvimento Humano - IDH considerado alto - 0,804 em 20004, o Plano Diretor do Município, elaborado no ano de 2006, evidencia algumas contradições, dentre as quais, evidencia-se que:

A renda per capita do município é inferior a um salário mínimo, não alcançando sequer a marca dos $\mathrm{R} \$ 320,00$. Assim, a taxa de pobreza, que indica o percentual de famílias com renda familiar per capita de até meio salário mínimo em relação ao número total de famílias residentes na área de estudo, é de 18,6, sendo a menor entre todos os municípios que compõem a mesorregião, sendo agravada quando comparada à do Paraná $(20,9)$. (PONTA GROSSA, 2006, p. 55).

Segundo o Instituto Paranaense de Desenvolvimento Econômico e Social - IPARDES -, a taxa de pobreza no município chegava em 2000 a 18,55\% $\%^{5}$ e o analfabetismo de pessoas com 15 anos ou mais, no ano de 2010, era de 3,69\% (embora o município tenha percebido, em 2011, reconhecimento como território livre do analfabetismo ${ }^{6}$.

Nesse contexto, também é importante destacar o estudo realizado por Nascimento (2008), o qual apresenta o crescimento da população favelada em Ponta Grossa, indicando que, em 2006, cerca de 51.845 pessoas viviam em favelas (17,27\% da população urbana), distribuídas em 136 pontos de ocupação. (NASCIMENTO, 2006).

Assim, a realidade de Ponta Grossa, cuja política de valorização do magistério se insere na presente reflexão, é contraditória, pois nela, a riqueza se faz presente no mesmo contexto da pobreza, o desenvolvimento econômico divide espaço com a desigualdade social. Mesmo com renda per capita que o coloca entre os municípios mais ricos do país, a população não tem acesso total aos serviços sociais básicos, como saúde e saneamento básico.

Tendo em vista o objetivo em que se insere a reflexão proposta, é preciso considerar que a carreira dos profissionais do magistério municipal, assim como ocorreu no contexto mais amplo, é matéria controversa e insere-se no contexto de luta pela valorização dos trabalhadores em geral.

\footnotetext{
${ }^{4} \mathrm{O}$ Índice de Desenvolvimento Humano - IDH é um indicador que varia de 0 a 1 . Quanto mais distante do 0 , maior o desenvolvimento humano.

${ }^{5}$ Segundo o IPARDES, o cálculo da população em situação de pobreza é realizado em função da renda familiar per capita de até $1 / 2$ salário mínimo. Os dados referentes à Situação de Pobreza são provenientes dos microdados do Censo Demográfico (IBGE) e das tabulações especiais feitas pelo IPARDES.

${ }^{6} \mathrm{O}$ artigo 11 do Decreto $\mathrm{n}^{\circ}$ 6.093, de 24 de abril de 2007 (BRASIL, 2007a), instituiu o Selo de Município Livre do Analfabetismo a ser concedido pelo Ministério da Educação aos municípios que atingirem mais de noventa e seis por cento de alfabetização, com base nos dados do Censo Demográfico do IBGE.
} 
O debate sobre a valorização dos profissionais da educação municipal, historicamente vinculou-se às discussões sobre a valorização dos servidores públicos municipais, conforme debates e lutas empreendidas pelo Sindicato dos Servidores Públicos Municipais de Ponta Grossa - SINDSERV.

É importante destacar que até o final da década de 80, a carreira do magistério municipal estava atrelada à legislação dos servidores em geral, Lei Municipal no 3.366 de $1^{\circ}$ de julho de 1981 (PONTA GROSSA, 1981), ou pela Consolidação das Leis Trabalhistas - CLT, conforme o regime de trabalho do servidor. Em 03 de novembro de 1988, entrou em vigor a Lei Municipal ${ }^{\circ}$ 4.213 (PONTA GROSSA, 1988) que dispunha sobre o Estatuto do Magistério Público Municipal, caracterizando-se como a primeira tentativa legal de organização da carreira docente no município em atendimento aos preceitos da Lei $\mathrm{n}^{\circ}$ 5.692/71 (BRASIL, 1971). A Lei Municipal no 4.213/88 (PONTA GROSSA, 1988) previa a organização da carreira em níveis ou classes conforme a formação dos profissionais (desde o professor com formação de nível médio até o professor com qualificação em nível de mestrado); a incorporação de um nível para os professores com titulação de doutorado ocorreu com a aprovação da Lei Municipal $n^{\circ} 4.372 / 90$ (PONTA GROSSA, 1990), com a incorporação de mais este nível na tabela salarial dos professores.

Em 24 de setembro de 1999, nova alteração ocorreu na estruturação da carreira docente municipal com a aprovação da Lei Municipal n ${ }^{\circ} 6.262$ (PONTA GROSSA, 1999), a qual criou o Regimento do Quadro Próprio do Magistério Público da Rede Municipal de Ensino e o respectivo plano de cargos, carreira e salários em atendimento ao disposto nas Leis $\mathrm{n}^{\circ} 9.394$ (BRASIL, 1996b) e n 9.424 (BRASIL, 1996c), relativas à Lei de Diretrizes e Bases da Educação Nacional e criação Fundo de Manutenção e Desenvolvimento do Ensino Fundamental e de Valorização do Magistério - FUNDEF. A Lei Municipal no 6.262/99 (PONTA GROSSA, 1999) retirou a formação em nível de mestrado e doutorado da tabela de vencimentos do quadro do magistério e criou um adicional de aperfeiçoamento para os professores com essa formação $(20 \%$ para professores mestres e 30\% para professores doutores sobre os respectivos rendimentos).

Nesse contexto de estruturação da carreira docente, houve o incentivo à formação para os professores sem a formação na graduação, através da possibilidade do recebimento de bolsas de estudo de natureza financeira para implementar esse nível de formação. Também para a formação stricto sensu os professores poderiam perceber ajuda financeira do poder municipal e afastamento das atividades docentes para o cumprimento dessa etapa. No entanto, no ano de 2003, houve readequação na norma que possibilitava o afastamento dos docentes para 
cursos de aperfeiçoamento em nível de mestrado e doutorado ${ }^{7}$, sendo que este último foi retirado da pauta de incentivo sob a justificativa governamental de que os professores da rede municipal não precisavam dessa formação.

Nova reestruturação da carreira docente municipal ocorreu com a Lei Municipal no 7.720/2004 (PONTA GROSSA, 2004), quando houve incorporação de gratificações existentes nas legislações anteriores, as quais eram recebidas por docentes regentes de classe, resolvendo uma distorção salarial existente entre os docentes regentes e não regentes.

Para situar a discussão que se pretende empreender, ao final do ano de 2004, a carreira docente estava organizada sob a égide da Lei Municipal $n^{\circ} 7.720$ (PONTA GROSSA, 2004), a qual estava assim estruturada: cinco níveis conforme formação dos professores: A - para profissionais com formação de nível médio; B - para profissionais com formação adicional de nível médio, $\mathrm{C}$ - para profissionais com graduação - licenciatura curta, D - para profissionais com graduação - licenciatura plena e E - para profissionais com formação em nível de pós-graduação - especialização. Aos profissionais com formação em nível de Mestrado ou Doutorado, havia a previsão de adicional de titulação na ordem de 20 e $30 \%$ sobre seus vencimentos, respectivamente.

Torna-se importante esclarecer que as reformulações legais ocorridas no período de 2001-2004 foram implementadas sob a administração do Partido dos Trabalhadores, a qual, embora não tivesse apoio total dos trabalhadores da educação, tinha importante base de sustentação junto aos servidores municipais. A incorporação das gratificações de regência de classe para todos os professores mostrou-se importante para a adesão dos profissionais às reformas implementadas, o que não ocorreu com o incentivo à formação, em razão do recuo quanto ao afastamento dos profissionais para aperfeiçoamento em nível de pós-graduação, através de licenças remuneradas, antes total e depois parcial, além do não incentivo à formação em nível de Doutorado. No entanto, a insatisfação relativa à falta de incentivo à formação em nível de doutorado não foi significativa em razão do pequeno número de profissionais interessados ou com possibilidade de reivindicarem tal formação. Esse recuo no incentivo à formação docente pode ser apontado como uma das causas de professores já titulados em nível de Mestrado optarem por deixar os quadros do magistério municipal, buscando adentrarem em outros campos de trabalho, principalmente em instituições de nível superior, públicas ou privadas.

O Decreto Municipal no 439/2003 (PONTA GROSSA, 2003) regulamentou o plano de capacitação docente com a concessão de incentivos aos docentes da rede municipal de ensino e secretários escolares, para cursos de graduação e pós-graduação lato sensu e stricto sensu, na área da educação. O respectivo decreto previa incentivos financeiros e/ou afastamento das atividades laborais para a frequência dos seguintes cursos: normal superior, graduação em pedagogia, especialização em educação e mestrado em educação (ficando o doutorado fora dessa regulamentação). 
Em uma perspectiva histórica e dialética, podemos considerar que houve avanços e também limites na política salarial do período 2001-2004. Em 2005, o novo governo (PSDB) inicia uma série de readequações administrativas e legais para garantir a governabilidade sob outros pressupostos de gestão pública. A política de valorização dos trabalhadores em educação não ficará ao largo desse novo entendimento.

A Lei Municipal no 7.720/2004 (PONTA GROSSA, 2004) permaneceu em vigor até o ano de 2010, organizando a carreira docente no contexto municipal até essa data. Assim, a ascensão salarial para professores de nível médio, graduados e especialistas, com carga horária de 20 horas semanais, ocorria conforme demonstrado no Gráfico 1, podendo estes, se portadores de títulos de Mestrado ou Doutorado, perceberem um adicional de 20 ou 30\% sobre o respectivo salário. No entanto, em face de falta de incentivo conforme exposto anteriormente, o município não contava com nenhum professor com titulação de doutor em seus quadros nesse período ${ }^{8}$.

Gráfico 1 - Avanço salarial vigente em 2010 - Lei no 7.720/2004 - Jornada de 20 horas semanais

\section{Salário \\ em reais}

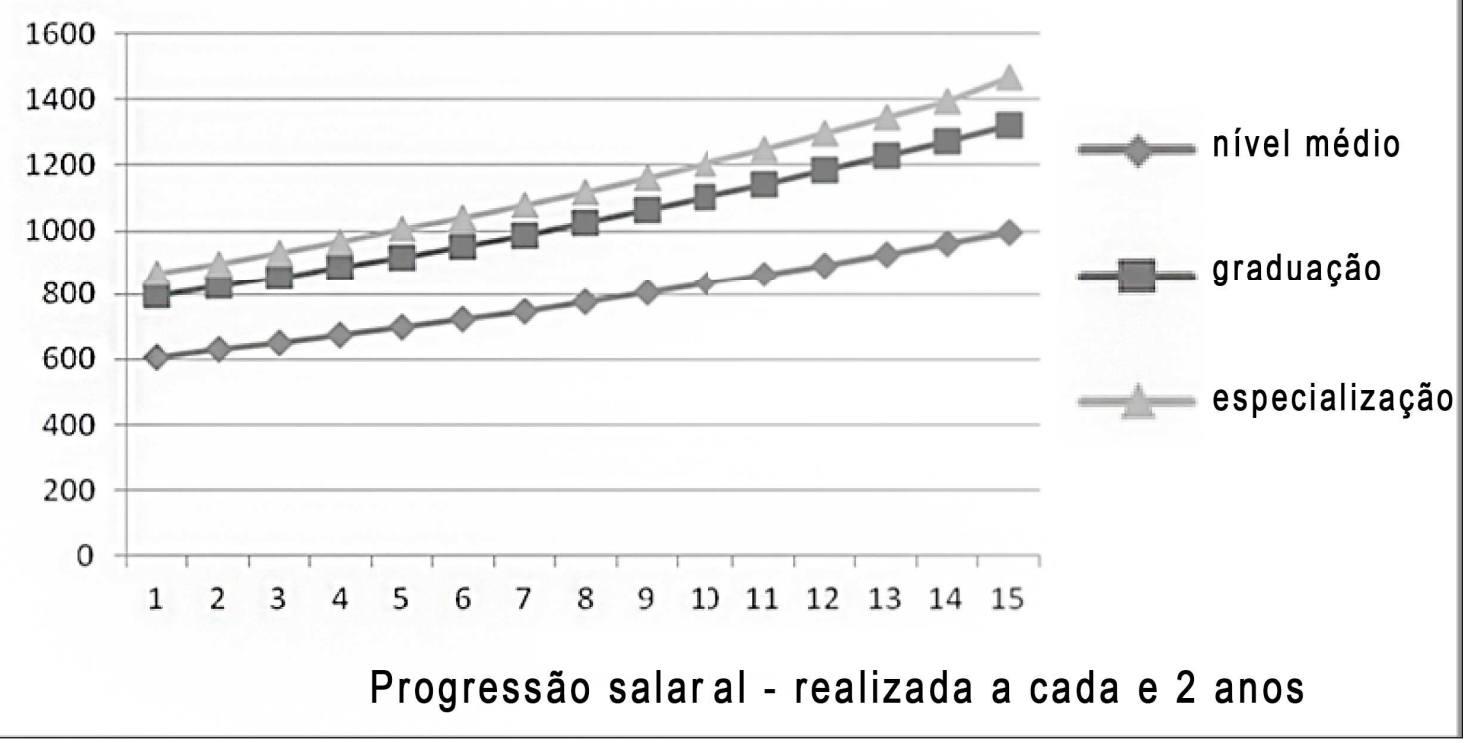

Fonte: Decreto Municipal n 4.033/2010 (PONTA GROSSA, 2010a). Gráfico organizado pela autora.

\footnotetext{
${ }^{8}$ Ao final de 2010, sob a vigência da Lei Municipal no 10.375/2010 (PONTA GROSSA, 2010b), o município teve uma professora que concluiu doutoramento em seu quadro docente. No entanto, pelos motivos já apontados, essa professora permaneceu no quadro municipal somente até meados de 2011.
} 
No entanto, o governo iniciado em 2005 (permanecendo no poder por 8 anos), pautado em uma abordagem de nova gestão pública, efetivou algumas adequações na legislação em vigor. Até a implementação da Lei Municipal $\mathrm{n}^{\circ}$ 10.375/2010 (PONTA GROSSA, 2010b), algumas alterações ocorreram na Lei Municipal $n^{\circ} 7.720 / 2004$ (PONTA GROSSA, 2004), modificando as relações existentes entre professores e governo municipal. Uma dessas modificações causou insatisfação na classe docente, face à modificação realizada no período compreendido como férias laborais. O texto da Lei $\mathrm{n}^{\mathrm{o}} 7.720 / 2004$, em seu art. 38, previa que "As férias dos professores serão de 30 (trinta) dias consecutivos em janeiro, acrescidos de 15 (quinze) dias usufruídos no período de recesso escolar, no mês de julho, e conforme calendário escolar, recesso em dezembro" (PONTA GROSSA, 2004). Esse artigo foi modificado em 2005 através da Lei Municipal no 8.430 (PONTA GROSSA, 2005), estabelecendo que "As férias dos Professores serão de 30 (trinta) dias consecutivos, podendo gozar de licença remunerada nos recessos escolares, tudo conforme dispuser a Secretaria Municipal de Educação.” Em um primeiro momento, a Administração Municipal aplicou o dispositivo legal de 2005 a todos os professores, no entendimento de que, a partir daquela data, todos os profissionais teriam direito apenas a 30 dias de férias no mês de janeiro. Esse fato causou inúmeras ações trabalhistas contra o governo municipal visando o cumprimento da previsão da Lei no 7.720/2004 (PONTA GROSSA, 2004) para os professores com vínculos anteriores a 2005.

A discussão jurídico-trabalhista centrou-se no fato de que a mudança do instrumento legal causou situações diferenciadas entre os professores contratados antes e depois do ano de 2005. A partir de então, o entendimento sobre a questão foi o seguinte: os professores com vínculos anteriores ao ano de 2005 tinham direito a 30 dias no mês de janeiro e 15 dias no mês de julho, conforme rezava a Lei $\mathrm{n}^{\circ} 7.720 / 2004$ (PONTA GROSSA, 2004), enquanto que professores detentores de novos vínculos profissionais passaram a gozar o período de férias de acordo com o que "dispusesse a Secretaria Municipal de Educação", conforme previsto na Lei no 8.430/2005 (PONTA GROSSA, 2005). A aplicação do direito de férias remuneradas e o pagamento de adicional sobre respectivo período ficou diferenciado. Os professores detentores de novos vínculos profissionais passaram a gozar o período de férias conforme estabelecido na Lei $\mathrm{n}^{\circ}$ 8.430/2005 percebendo remuneração diferenciada aos profissionais com vínculos mais antigos. A estratégia governamental de alteração jurídico-normativa sobre o direito dos trabalhadores demonstra a vinculação com uma nova forma de administrar a coisa pública, a qual defende o compromisso com novas competências e novas estratégias administrativas, através de práticas gerenciais modernas, dentre as quais a redução de custos representa centralidade. A adoção de estratégias de redução de custos por intermédio da reorganização 
da remuneração dos profissionais, nessa perspectiva, não parece ser um limitador para a garantia da governabilidade e governança ${ }^{9}$.

É sob esse novo enfoque que ocorre a adequação, a qual denominamos de reforma da carreira docente no contexto municipal pesquisado. Assim, em 2010, sob a responsabilidade de consultores contratados para esse fim, o governo municipal apresenta uma nova proposta de carreira docente. Essa nova proposta, depois de concluída pela equipe de consultores, foi apresentada à equipe de gestão das escolas (que tiveram sob o seu encargo o repasse aos docentes nas unidades escolares) e enviada ao Legislativo Municipal, sendo transformada na Lei Municipal no 10.375/2010 (PONTA GROSSA, 2010b), sem discussões significativas sobre o seu impacto ao longo da carreira dos profissionais.

A Lei no 10.375/2010 (PONTA GROSSA, 2010b) reorganizou a carreira agrupando os docentes em dois grupos. O grupo 1, denominado de quadro permanente, composto por profissionais a ingressarem na carreira docente conforme critérios específicos e profissionais da educação infantil que até então permaneciam no quadro geral dos servidores e que concluíssem o curso de Licenciatura Plena. O grupo 2, denominado de quadro especial em extinção e em transição, composto pelos profissionais já integrantes da carreira docente, conforme sua titulação (inclusive os professores de Educação Infantil sem a formação de graduação em Licenciatura Plena). Nessa nova organização, o ingresso na carreira docente é previsto apenas para profissionais graduados em Licenciatura em Pedagogia, Normal Superior ou outra licenciatura, desde que formados em cursos de formação de professores em nível médio ${ }^{10}$. A exigência de profissionais formados em curso de graduação pode ser considerada um avanço em relação às demais regiões do país, pois a previsão de profissionais habilitados tem se mostrado como uma referência positiva para a busca da qualidade educativa.

Tendo organizado o quadro docente em dois grupos, a reforma implementada pela Lei $n^{\circ}$ 10.375/2010 (PONTA GROSSA, 2010b) criou situações diferenciadas em razão da formação e ingresso previsto nas legislações anteriores, situando os profissionais sem a formação superior no quadro especial em extinção e em transição. Dessa forma, para o estudo aqui proposto, foram consideradas as possibilidades de avanço salarial no quadro permanente, por ser aquele que permite visualizar como o professor alcançará melhores condições salariais ao longo de sua carreira.

\footnotetext{
${ }^{9}$ Segundo Luiz Carlos Bresser Pereira (2006), a reforma do Estado envolve aspectos políticos, econômicos e administrativos. Os aspectos políticos, como transformar suas políticas em realidade, promovem a governabilidade e os aspectos econômicos e administrativos, como o ajuste fiscal e reorganização do serviço público, garantem a governança.

${ }^{10}$ A exigência do curso de formação de docente em nível médio restou prevista apenas para os licenciados nas diversas áreas do conhecimento.
} 
O novo Plano de Carreira implementado pela Lei Municipal $n^{\circ}$ 10.375/2010 (PONTA GROSSA, 2010b) teve, portanto, a previsão salarial inicial a partir da formação em nível superior, prevendo readequação conforme a titulação do profissional em nível de pós-graduação lato sensu (especialização) e stricto sensu (mestrado), sendo este incorporado à tabela salarial, sem previsão de pagamento de adicional como na legislação anterior. A carga horária dos profissionais também foi alterada, podendo ser de 20 ou 40 horas semanais, conforme atuação nos anos iniciais do ensino fundamental ou educação infantil, respectivamente.

Para a análise aqui apresentada, considerou-se apenas o avanço salarial para os professores com jornada de trabalho de 20 horas semanais, por ser aquele passível de comparação com a realidade existente anteriormente, conforme se verificará. $\mathrm{O}$ avanço salarial ao longo da carreira docente, a partir da Lei Municipal n 10.375/2010 (PONTA GROSSA, 2010b), pode ser observado no Gráfico 2:

Gráfico 2 - Avanço salarial vigente a partir da Lei no 10.375/2010 - Para jornada de 20 horas semanais

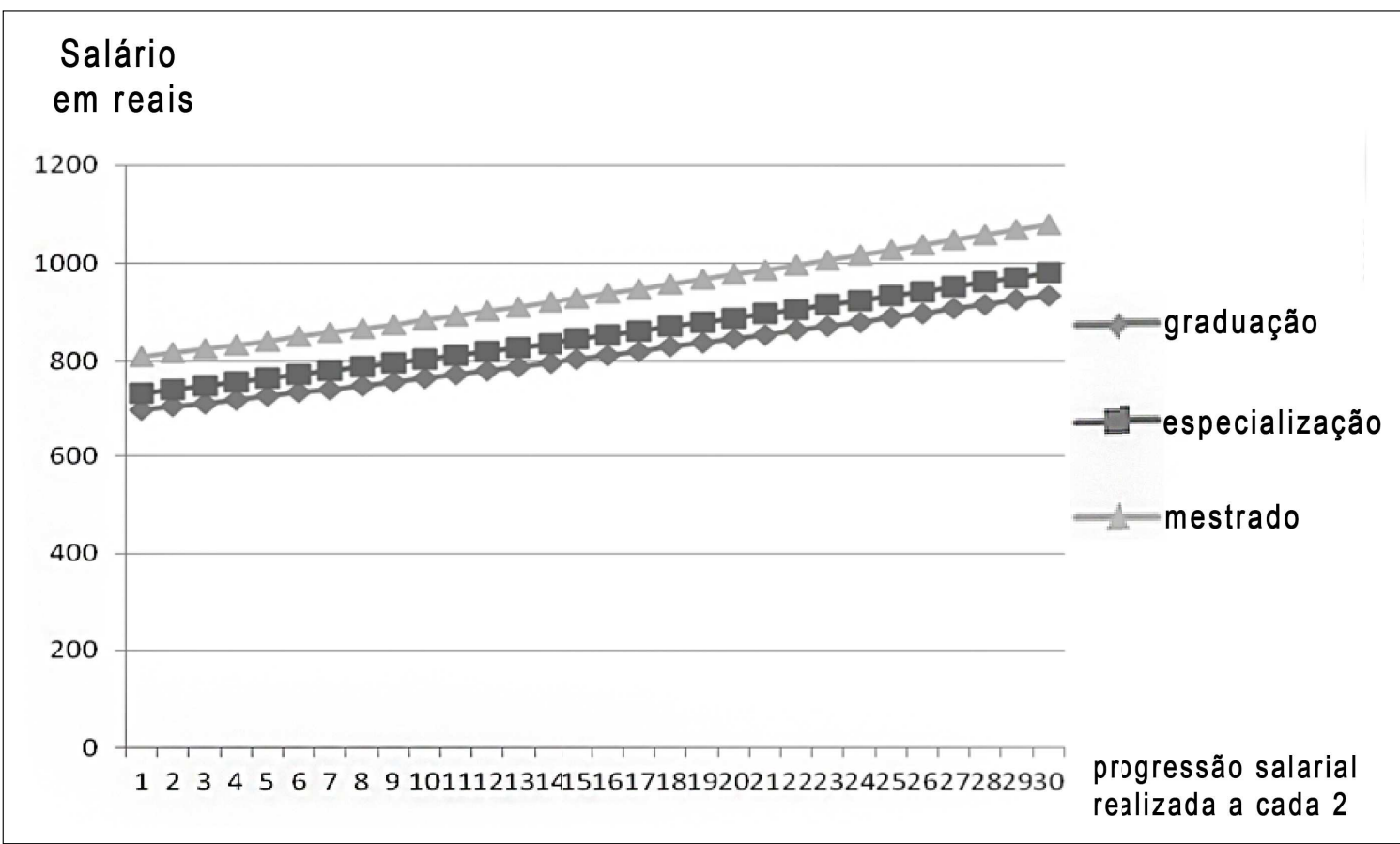

Fonte: Lei Municipal no 10.375/2010 (PONTA GROSSA, 2010b) - Anexo III - Quadro Permanente. Gráfico organizado pela autora.

Em relação ao adicional de titulação existente anteriormente, este foi incorporado à previsão salarial para os detentores de título de mestrado e, para os profissionais com titulação de doutorado, houve alteração significativa com a previsão de gratificação conforme previsto no art. 61 da referida lei: 
"O profissional do magistério que concluir curso de pós-graduação em nível de Doutorado faz jus à gratificação de trinta por cento, calculada sobre o vencimento inicial da carreira de Professor correspondente à respectiva jornada de trabalho" (PONTA GROSSA, 2010b). Essa previsão pode ser apontada como um incentivo desestimulante à busca de maior formação, pois enquanto a lei anterior previa pagamento de adicional de titulação na ordem de $30 \%$ sobre os vencimentos do professor, a reforma em curso reduziu essa possibilidade para o vencimento inicial da carreira docente.

A diferença na possibilidade de avanço salarial ao longo da carreira entre a realidade anterior a 2010 e aquela que se configurou a partir dessa data pode ser visualizada no comparativo realizado com base no Gráfico 3, o qual possibilita melhor entendimento das questões apontadas. A referência utilizada para a configuração do Gráfico 3 foi o salário dos professores com formação em nível superior - graduação, antes e depois da Reforma de 2010 ao longo da carreira.

Gráfico 3 - Avanço salarial de professores com Graduação - Antes e depois da reforma de 2010 - Jornada de 20 horas semanais

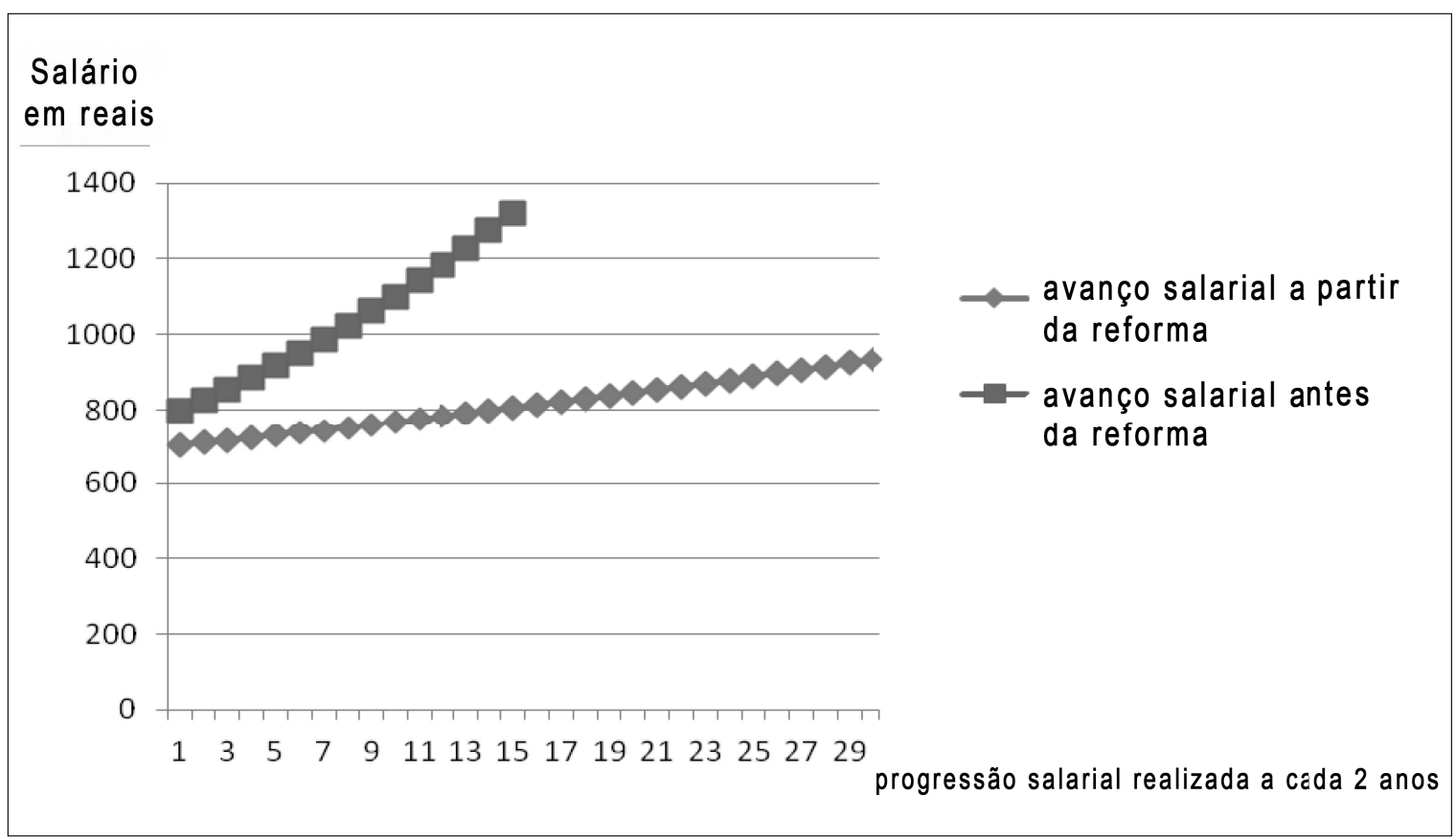

Fonte: Lei Municipal no 10.375/2010 (PONTA GROSSA, 2010b) - Anexo III - Quadro Permanente e Decreto Municipal n 4.033/2010 (PONTA GROSSA, 2010a). Gráfico organizado pela autora.

O Gráfico 3 demonstra, ainda, que o avanço salarial por tempo de serviço antes e depois da reforma de 2010 é visualmente desigual. Antes do ano de 2010, a possibilidade de chegar ao salário final da carreira, com avanços bianuais, era muito mais atrativa. Após a reforma de 2010, o avanço salarial na 
carreira tornou-se moroso. Ao se considerar os valores reais ao longo da carreira docente, pode-se ter uma visão da desvalorização profissional ocorrida.

Quadro 1 - Comparativo salarial - Professores com Graduação - Jornada de 20 horas semanais

\begin{tabular}{|c|c|c|}
\hline & ANTES da Reforma & DEPOIS da Reforma - 2010 \\
\hline Salário no INÍCIO da carreira & $\mathbf{7 9 6 , 4 0}$ & $\mathbf{7 0 0 , 0 0}$ \\
\hline Salário ao FINAL da carreira & $\mathbf{1 . 3 2 2 , 3 9}$ & $\mathbf{9 3 4 , 1 5}$ \\
\hline
\end{tabular}

Fonte: Lei Municipal no 10.375/2010 (PONTA GROSSA, 2010b) - Anexo III - Quadro Permanente e Decreto Municipal no 4.033/2010 (PONTA GROSSA, 2010a). Quadro organizado pela autora.

Contraditoriamente, a reforma implementada pode ser considerada um avanço quando se defende o ingresso na carreira docente para os profissionais com graduação, enquanto na realidade anterior, o ingresso ocorria para os detentores de titulação de nível médio na modalidade normal. Também a questão salarial não é menos importante, pois com um salário inicial de R $\mathbf{6 0 8 , 3 6}$ (para professores com formação de nível médio), conforme previsto no Decreto Municipal $n^{\circ}$ 4.033/2010 (PONTA GROSSA, 2010a) (referente ao reajuste de salários conforme data base de 2010), a previsão de $\mathrm{R} \$ 700,00$, estabelecida no Anexo III da Lei Municipal no 10.375/2010 (PONTA GROSSA, 2010b) parece, grosso modo, um pequeno avanço. É preciso considerar que, mesmo com proibição legal de redução salarial, houve redução salarial para o ingresso na carreira dos professores detentores de graduação. Essa estratégia considerou apenas o salário inicial para o ingresso na carreira, sem considerar a titulação do ingressante. Ou seja, o salário inicial da carreira antes da reforma era de $\mathrm{R} \$ 608,36$ e depois da reforma passou a ser de $\mathrm{R} \$ 700,00$. No imbróglio de interpretações legais, o salário dos professores ingressantes na carreira docente foi visceralmente reduzido.

Os efeitos da Reforma implementada pela Lei Municipal no 10.375/2010 (PONTA GROSSA, 2010b) se tornaram visíveis a partir da contratação de novos professores em 2011, quando os profissionais já detentores de um vínculo laboral tiveram um novo contrato de trabalho e puderam visualizar na prática o que significou a nova reestruturação da carreira docente. Da mesma forma, ocorreu quando um grande número de profissionais ingressantes na carreira docente nela não permaneceu, buscando alternativas de trabalho em outras áreas ou em redes privadas de ensino ${ }^{11}$.

\footnotetext{
${ }^{11}$ No final de 2010, o município realizou concurso público para a contratação de professores, tendo 915 aprovados para o cargo professor 20 horas semanais. Esses aprovados foram convocados para contratação durante o ano de 2011, sendo a lista de classificados esgotada (muitos por desistência antes ou depois da contratação). No primeiro semestre de 2012, outro concurso foi realizado, sendo que 281 profissionais foram aprovados para o cargo de 20 horas semanais.
} 


\section{Pressupostos gerenciais na reorganização da carreira docente}

Embora a análise dos pressupostos que norteiam a ação no período não seja o objetivo central da exposição empreendida, evidencia-se que a reforma legal realizada para a adequação da carreira docente demonstra vínculo explícito com a concepção de uma nova gestão pública, ou seja, com a administração pública gerencial.

Convém ressaltar que a administração pública gerencial não é um modo novo de agir na área pública, tendo emergido nos países centrais na década de 1970 como estratégia para reduzir o custo e tornar mais eficiente a administração dos serviços sob a responsabilidade do Estado, contrapondo-se a uma administração pública burocrática (BRESSER-PEREIRA, 2006). Na realidade brasileira, a administração pública gerencial não é nova. Ela ganhou força a partir de 1990, após o período de hiperinflação da década de 1980, a reorganização constitucional ocorrida em 1988 e a redemocratização do país após o período da ditadura militar. A configuração social e política do período foi solo fértil para os pressupostos gerenciais se solidificarem em prol de administradores públicos mais autônomos e a oferta de serviços públicos descentralizados ${ }^{12}$ independentemente da concepção ideológica que norteava as ações governamentais de estados e municípios. Isso ocorreu em especial a partir de 1995, com o governo de Fernando Henrique Cardoso. A reforma implementada naquele período visava, em linhas gerais, realizar um ajuste fiscal a curto prazo e tornar a administração pública moderna e eficiente a médio prazo. Os pressupostos gerenciais na administração pública se propagaram rapidamente em todo o país, visto que estados e municípios de maneira geral buscavam corrigir o déficit público e tornar os serviços oferecidos à população mais eficientes. Os efeitos da adesão ao gerencialismo se mostraram profundos, principalmente para os quadros do funcionalismo público, em todas as esferas da administração.

Um pressuposto de diferenciação entre a administração pública burocrática e a gerencial é que aquela se concentrava no processo, sendo autorreferente, enquanto esta se orienta para os resultados. Essa nova gestão pública exige o compromisso com novas competências e novas estratégias administrativas, através de práticas gerenciais modernas, as quais se tornam instrumentos eficazes para cumprir sua função eminentemente pública, conforme abordado por Bresser-Pereira e Spink (2006, p. 7). Nessa perspectiva, o aparato burocrático

\footnotetext{
${ }^{12}$ Um exemplo exitoso, segundo Bresser-Pereira (2010), da reforma gerencial, ocorrido após o período de 1995 e presente nos dias atuais, é o Sistema Único de Saúde - SUS. O SUS, criado pela Constituição Federal de 1988 para garantir o direito universal aos serviços de saúde, passou por uma grande reforma gerencial em 1996. Ao longo dos anos, o Sistema passou a atender um grande número de pessoas por um baixo custo. Atualmente, os municípios exercem papel fundamental na execução de contratos de gestão com hospitais que prestam os serviços e o controle social é exercido pelos cidadãos.
} 
de uma abordagem conservadora é substituído por uma abordagem "gerencial", onde o gerenciar é visto como a capacidade de estabelecer novas estratégias que garantam a governabilidade a curto e médio prazo. Isso pode significar tornar as ações mais eficientes e, na maioria dos casos, com menor custo. Para tanto, algumas estratégias se mostram eficazes: prever ações voltadas para os cidadãos, priorizar a descentralização, incentivar a criatividade e a inovação e ainda controlar os gestores públicos através de contratos de gestão.

No município pesquisado, a reorganização da carreira docente demonstra estar atrelada a esses pressupostos gerenciais, uma vez que

A reforma da administração pública será executada em três dimensões: a) a institucional-legal, por meio da qual se modificam as leis e se criam ou modificam instituições; b) a cultural, baseada na mudança dos valores burocráticos para os gerenciais; e c) a da co-gestão. (BRESSER-PEREIRA, 2006, p. 265).

Na perspectiva apontada por Bresser-Pereira (2006), a reforma institucional-legal mostrou-se essencial para a reorganização da carreira docente no município pesquisado; a reforma na dimensão cultural pode ter ocorrido de forma implícita, visto que não houve manifestação significativa dos sujeitos envolvidos contra a nova organização da carreira; e a co-gestão pode ser identificada quando as equipes gestoras das unidades escolares foram envolvidas na divulgação da nova proposta, possibilitando o falso entendimento de participação no processo. Essa visão equivocada colabora para um entendimento de que os serviços educacionais prestados à população estão sendo controlados financeiramente e, consequentemente, os resultados obtidos serão de melhor qualidade.

A falta de discussão e forma fechada como ocorreu o planejamento da reestruturação da carreira docente, por intermédio de contratação de consultoria especializada para esse fim, reafirma que na perspectiva adotada de uma nova gestão pública se mostra bem ao sabor de que para governar "é preciso liderança, é necessário haver um processo progressivo de convencimento", ou ainda, "a legitimidade da decisão tem que caber àqueles que são os detentores da vontade popular. Esta é a essência da democracia; essa é a essência do republicanismo." (CARDOSO, 2009, p. 17).

O resultado da reforma legal implementada na carreira docente no município pesquisado, segundo o entendimento gerencial, tem saldo positivo, visto que houve redução significativa de custos em médio prazo, pois os profissionais já integrantes da carreira não tiveram seus salários reduzidos, mas os ingressantes não terão o mesmo avanço salarial e as condições adequadas para buscar melhor qualificação. E, na mesma esteira de entendimento, há possibilidade de ampliação do atendimento do serviço educacional, pois a contratação de um número maior de profissionais cria a possibilidade de ampliação e melhoria do 
atendimento. Entretanto, é preciso entender que isso seria possível em condições ideais, mas considerando a realidade educacional do país (e a do município não é muito diferente), onde a implementação de políticas impõe a ampliação de vagas, a inclusão de alunos com algum tipo de deficiência; a ampliação do tempo escolar; além da assunção de responsabilidades não explicitamente escolares, a contratação de mais profissionais com salários menores não parece ser a melhor alternativa para transformar o atendimento educacional oferecido à população.

\section{Considerações finais}

A valorização dos professores brasileiros sempre foi matéria controversa. Diferentes posturas ideológicas podem orientar as ações políticas voltadas para a questão salarial do professor, contudo, sem a resolver. Em uma sociedade capitalista como a brasileira, é preciso compreender os professores enquanto profissionais que vendem a sua força de trabalho para garantir a própria sobrevivência. Compreender essa questão em sua essência modifica a forma de analisar as investidas gerenciais na organização dos planos de carreira do magistério público brasileiro. Não é possível analisar a implementação de reformas legais sem vislumbrar seus efeitos na vida dos trabalhadores que serão afetados por elas.

A análise precisa ser radical, demonstrando o movimento real entre o singular e o universal, e como tal, eivado de contradições.

A busca por melhor oferta educacional, através de profissionais mais habilitados, pode ser apontada como um avanço. Avanço esse que se mostra contraditório quando se contrapõe à exigência de formação em nível superior com o salário inicial para professores ingressantes na carreira, havendo descompasso entre o exigido e a contrapartida oferecida. A organização da carreira docente no município pesquisado demonstra ligação aos pressupostos do novo gerencialismo, quando, com base em uma reforma legal, conseguiu instituir situações diferenciadas para a mesma classe de trabalhadores, conseguindo, por um lado, a adesão dos já integrantes da carreira e, por outro, tornando essa carreira pouco atrativa aos novos profissionais.

Cumpre ressaltar que a adesão aos pressupostos do novo gerencialismo não oferece possibilidades ao funcionalismo de alteração do instituído pelos gestores públicos, a não ser no campo sempre presente da luta dos trabalhadores por melhores condições de trabalho e de vida, onde se insere a questão salarial aqui relatada. 
A possibilidade que se vislumbra em terreno tão contraditório é aquela que se dá no campo da luta de classes, onde a questão precisa ser debatida e perseguida, pois no campo governamental, a luta é impossível, principalmente quando os gestores públicos já aderiram a tais orientações. Por isso, ressalta-se a importância dos órgãos representativos dos professores para não perderem o foco de discussão, mobilizando, esclarecendo, trazendo tais profissionais para o campo do debate. Somente a compreensão dos efeitos de propostas salariais, muitas vezes enganosas, pode colaborar para a união desses trabalhadores em prol de objetivos comuns.

\section{Referências}

ALMEIDA, J. S. de. Mulheres na educação: missão, vocação e destino? A feminização do magistério ao longo do século XX. In: SAVIANI, D. et al. O legado educacional do século XX no Brasil. Campinas, SP: Autores Associados, 2004. p. 59- 107.

BRASIL. Lei no 5.692, de 11 de agosto de 1971. Fixa as Diretrizes e Bases para o ensino de $1^{\circ}$ e $2^{\circ}$ graus e dá outras providências. Diário Oficial da União, Brasília, 12 ago. 1971, Seção 1, p. 6377.

Constituição da República Federativa do Brasil de 1988. Disponível em: $<$ http://www.planalto.gov.br/ccivil_03/constituicao/constituicaocompilado.htm>. Acesso em 13 ago. 2012.

Emenda constitucional $\mathrm{n}^{\circ}$ 14, de 12 de setembro de 1996. Modifica os arts. 34, 208, 211 e 212 da Constituição Federal e dá nova redação ao art. 60 do Ato das Disposições constitucionais Transitórias. Diário Oficial da União, Brasília, 13 set. 1996a, Seção 1, p. 18109.

Lei $\mathrm{n}^{\circ}$ 9.394, de 20 de dezembro de 1996. Estabelece as Diretrizes e Bases da Educação Nacional. Diário Oficial da União, Brasilia, 23 dez. 1996b.

Lei ${ }^{\circ}$ 9.424, de 24 de dezembro de 1996. Dispõe sobre o Fundo de Manutenção e Desenvolvimento do Ensino Fundamental e de Valorização do Magistério, na forma prevista no art. $60, \int 7^{\circ}$, do Ato das Disposições Constitucionais Transitórias, e dá outras providências. Diário Oficial da União, Brasília, 26 dez. 1996c, Seção 1, p. 28442.

Emenda constitucional no 53 , de 19 de dezembro de 2006. Dá nova redação aos arts. $7^{\circ}, 23,30,206,208,211$ e 212 da Constituição Federal e ao art. 60 do Ato das Disposições Constitucionais Transitórias. Diário Oficial da União, Brasília, 20 dez. 2006.

Decreto $\mathrm{n}^{\circ}$ 6.093, de 24 de abril de 2007. Dispõe sobre a reorganização do Programa Brasil Alfabetizado, visando a universalização da alfabetização de jovens e adultos de quinze anos ou mais, e dá outras providências. Diário Oficial da União, Brasília, 25 abr. 2007a, Seção 1, p. 4.

Lei no 11.494, de 20 de junho de 2007. Regulamenta o Fundo de Manutenção e Desenvolvimento da Educação Básica e de Valorização dos Profissionais da Educação FUNDEB, de que trata o art. 60 do Ato das Disposições Constitucionais Transitórias; altera a Lei $n^{\circ}$ 10.195, de 14 de fevereiro de 2001; revoga dispositivos das Leis $n^{o s}$ 9.424, de 24 de 
dezembro de 1996, 10.880, de 9 de junho de 2004, e 10.845, de 5 de março de 2004; e dá outras providências. Diário Oficial da União, Brasília, 21 jun. 2007b, Seção 1, p. 7.

Lei no 11.738 , de 16 de julho de 2008. Regulamenta a alínea "e" do inciso III do caput do art. 60 do Ato das Disposições Constitucionais Transitórias, para instituir o piso salarial profissional nacional para os profissionais do magistério público da Educação Básica. Diário Oficial da União, Brasília, 17 jul. 2008, Seção 1, p. 20.

BRESSER-PEREIRA, L. C. Da administração pública burocrática à gerencial. In: BRESSERPEREIRA, L. C.; SPINK, P. (Orgs.). Reforma do Estado e Administração Pública Gerencial. 7. ed. Rio de Janeiro: Editora FGV, 2006. p. 237- 270.

Democracia, estado social e reforma gerencial. Revista de Administração de Empresas, São Paulo, v. 50, n. 1, p. 112-116, jan./mar. 2010.

CAMPOS, M. C. S. D. S. Formação do corpo docente e valores na sociedade brasileira: a feminização da profissão. In: CAMPOS, M. C. S. D. S.; SILVA, V. D. G. D. (Eds.). Feminização do magistério: vestígios do passado que marcam o presente. Bragança Paulista: Edusf, 2002. p. $13-37$.

CARDOSO, F. H. Reforma do estado. In. BRESSER-PEREIRA, L. C.; SPINK, P. (Orgs.). Reforma do estado e administração pública gerencial. 7. ed. Rio de Janeiro: Editora FGV, 2006. p. 15- 19.

FERREIRA JR., A.; BITTAR, M. Proletarização e sindicalismo de professores na ditadura militar (1964-1985). São Paulo: Terras do Sonhar: Edições Pulsar, 2006.

MINHOTO, M. A. P.; PENNA, M. G. de O. Valorização do magistério ou darwinismo profissional? Ensaio: Avaliação e Políticas Públicas em Educação, Rio de Janeiro, v. 19, n. 70, p.149-164, jan./mar. 2011.

NASCIMENTO, E. Espaço e desigualdades: mapeamento e análise da dinâmica de exclusão/inclusão social na cidade de Ponta Grossa (PR). 2008. 136 f. Dissertação (Mestrado em Gestão do Território) - Universidade Estadual de Ponta Grossa, Ponta Grossa, 2008.

PONTA GROSSA. Lei $\mathbf{n}^{\mathbf{0}} \mathbf{3 . 3 6 6}$, de 01 de julho de 1981. Dispõe sobre o estatuto dos funcionários públicos do município de ponta grossa, estado do Paraná. Ponta Grossa, 1981.

Lei $\mathbf{n}^{\circ}$ 4.213, de 03 de novembro de 1988. Dispõe sobre o Estatuto do Magistério Público Municipal de Ponta Grossa. Ponta Grossa, 1988.

Lei $\mathbf{n}^{\circ}$ 4.372, de 09 de maio de 1990. Altera a lei $n^{\circ}$ 4213, de 03/11/88, Estatuto do Magistério Público Municipal. Ponta Grossa, 1990.

Lei $\mathbf{n}^{\circ}$ 6.262, de 24 de setembro de 1999. Aprova o Regimento do Quadro Próprio do Magistério Público da Rede Municipal de Ensino e o respectivo Plano de Cargos, Carreira e Salários. Ponta Grossa, 1999.

Decreto Municipal $\mathbf{n}^{\circ}$ 439, de 20 de agosto de 2003. Regulamenta o plano de capacitação docente com a concessão de incentivos pela PMPG aos docentes do QPE da rede municipal de ensino e secretários escolares, para cursos de graduação e pós-graduação lato sensu e stricto sensu, na área da educação. Ponta Grossa, 2003.

Lei $\mathbf{n}^{\mathbf{0}} \mathbf{7 . 7 2 0}$, de 28 de julho de 2004. Aprova o Regimento do Quadro Próprio dos Profissionais da Rede Municipal de Ensino e o Respectivo Plano de Cargos, Carreira e Salários. Ponta Grossa, 2004. 
Lei $\mathrm{n}^{\circ} \mathbf{8 . 4 3 0}$, de 29 de dezembro de 2005. Altera o caput do artigo 38, da Lei 7.720/2004 e dá nova redação ao artigo $8^{\circ}$ da Lei 6.850/2001. Ponta Grossa, 2005.

Plano Diretor Participativo Município de Ponta Grossa. Ponta Grossa, 2006. Disponível em: <http://www.pontagrossa.pr.gov.br/planodiretor>. Acesso em: 15 maio 2013.

Decreto Municipal $\mathbf{n}^{\circ}$ 4033, de 12 de maio de 2010. Dispõe sobre o reajuste dos vencimentos, salários, gratificações e proventos do funcionalismo público municipal, a partir de $1^{\circ}$ de maio de 2010. Ponta Grossa, 2010a.

Lei $\mathrm{n}^{\circ} \mathbf{1 0 . 3 7 5}$ de 28 de setembro 2010. Dispõe sobre e o plano de empregos, carreira e remuneração do magistério público municipal de Ponta Grossa. Ponta Grossa, $2010 \mathrm{~b}$.

RABELO, A. O. A remuneração do professor é baixa ou alta? Uma contraposição de diferentes referenciais. Educação em Revista, Belo Horizonte, v. 26, n. 1, p. 57-87, abr. 2010.

TANURI, L. M. História da formação de professores. Revista Brasileira de Educação, Rio de Janeiro, n. 14, p. 61-88, maio/ago. 2000.

Recebido em 10/09/2012

Versão final recebida em 30/05/2013

Aceito em 03/06/2013 